\title{
Estimated egg production of Fasciola gigantica (Japanese strain) in goats experimentally infected with 50 metacercariae
}

\author{
K. TAIRA ${ }^{1 *}$, Y. SAITOH ${ }^{1}$ \\ ${ }^{1}$ Laboratory for Parasitology, Department of Veterinary Medicine, Azabu University, Sagamihara, \\ Kanagawa 229-8501, Japan, E-mail: taira@azabu-u.ac.jp
}

\begin{abstract}
Summary
Egg production capacity in Fasciola gigantica (Japanese strain) was estimated from egg count data obtained by the experimental infection of two goats. The goats were inoculated with a single dose of 50 metacercariae. The first goat was necropsied 132 days after infection (DAI) and the second goat 732 DAI. After patency, daily faecal production was collected and weighed and number of eggs per gram was counted. At necropsy, 23 flukes were recovered from the liver of the first goat, and five from the second goat. The mean number of eggs produced per day per worm ( $\pm 95 \%$ confidence limits) was $9477.9( \pm 764.92)$ for the first goat at 106 to $132 \mathrm{DAI}$, and 8,064.1 $( \pm 416.49)$ at 195 to $561 \mathrm{DAI}$ for the second goat. The number of eggs produced per day per worm in $F$. gigantica (Japanese strain) has thus reached values ranged from approximately 8000 to 10000 eggs.
\end{abstract}

Keywords: Fasciola gigantica (Japanese strain); goats; experimental infection; egg production capacity; fecundity

\section{Introduction}

Estimation of the number of flukes present in livestock based on faecal egg counts is important for the diagnosis of chronic fasciolosis. Knowledge of the egg production capacity of Fasciola may also facilitate the evaluation of anthelmintic treatment efficacy and provide guidelines for epidemiological studies. A variety of factors is known to influence the egg production capacity in Fasciola, such as age, number or isolate of the parasite (Boray, 1967; Walker et al., 2006) and/or hosts species (Alicata \& Swanson, 1941).

The taxonomy of Fasciola species circulated in Japan has not yet been thoroughly classified and is still under considerable debate. The morphological characteristics of the Japanese forms of Fasciola are usually corresponding to $F$. gigantica and/or $F$. hepatica, and are often similar to both species (Itagaki \& Tsutsumi, 1998). In a recent comprehensive genetic study on Fasciola from 16 Japanese prefectures, Itagaki et al. (2005) recorded 2 major forms that are identical or closely related to $F$. hepatica and $F$. gigantica and 3 minor forms, one of which was attributed to hybrid form likely originated from paternal $F$. hepatica and maternal $F$. gigantica. Fasciola isolate used in the present study is referred to as " $F$. gigantica (Japanese strain)" as a Fasciola sp. in Japan, following the method of Yoshihara et al. (1998) and Taira et al. (2000). The egg production capacity, such as the number of eggs produced per day per worm (EPDPW) of $F$. gigantica (Japanese strain), estimated using quantitative egg count data in experimental infection studies, has not been so far reported.

The aim of the present study was therefore to estimate the EPDPW in $F$. gigantica (Japanese strain) using data gathered in previous studies (Taira et al., 2000). In this report, EPDPW data were extensively analysed to estimate the egg production capacity of this fluke.

\section{Materials and methods}

Infection with Fasciola metacercariae

Two goats were used in the experimental study. Information on the experimental design and the infection of the first goat (No. 802) and the second goat (No. 602) was previously described (Taira et al., 2000). Briefly, goat No. 802 (18.5 kg body weight) and goat No. $602(12.2 \mathrm{~kg})$ were inoculated with a single dose of 50 metacercariae of $F$. gigantica (Japanese strain) (Taira et al., 1997). The goats were raised indoors in metabolism cages with grilled floors, and fed only with cubed hay and concentrated grain to preclude natural infection. Goats were maintained with due regard for their welfare.

\section{Necropsy}

Goats Nos. 802 and 602 were necropsied at 132 DAI and 


\section{Goat No.802}

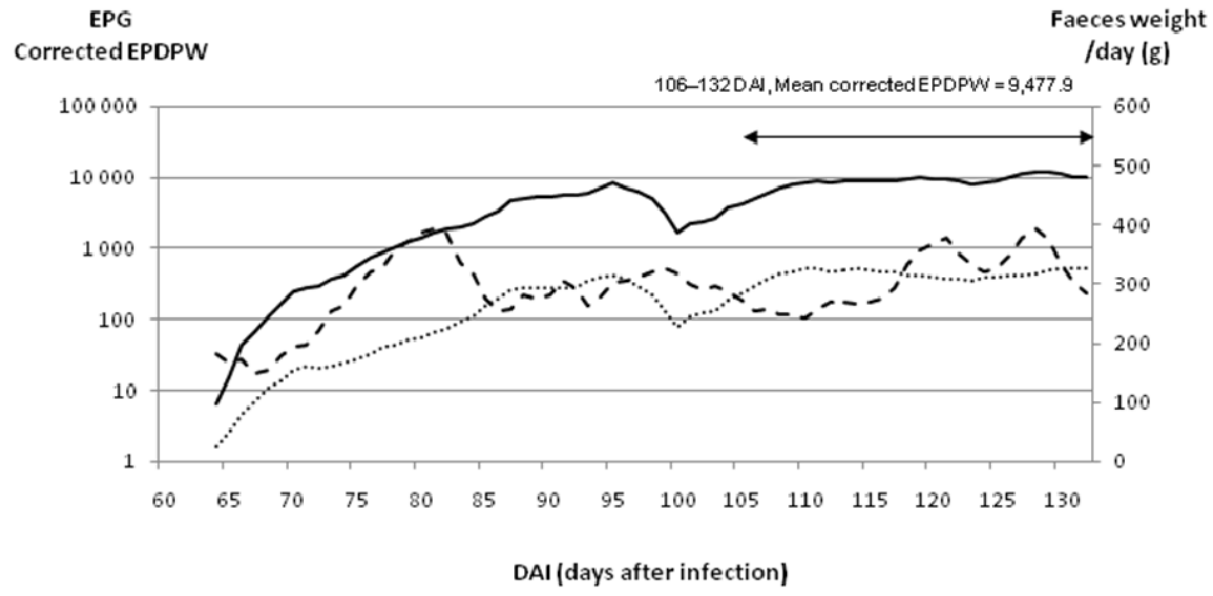

Fig. 1. Variation in daily feces weight (broken line), eggs per gram (EPG) (dotted line) and corrected EPDPW (solid line) in a goat (No.802) experimentally infected with a single dose of 50 metacercariae of Fasciola gigantica (Japanese strain). Lines represent the moving average $(\mathrm{n}=5)$. The goat was necropsied 132 days after infection (DAI) and 23 worms were detected.

Mean corrected EPDPW = feces weight in a day $(\mathrm{g}) \mathrm{x}$ EPG / number of worms detected at necropsy x 100/63.6 (see text). Mean corrected EPDPW was calculated for the period indicated by the both end arrow.

732 DAI, respectively. On the day of necropsy, the body weights of goats were measured and the macroscopical lesions of the goat livers were recorded. The number of flukes in the liver was counted at necropsy and the wet weight of the flukes from each animal was recorded.

\section{Faecal egg counts}

After patency, all faeces excreted in a day were collected and weighed. One gram of faeces of all samples was preserved in a $5 \%$ formalin solution (Bonita \& Taira, 1996). The number of eggs per gram (EPG) of faeces was counted using the beads technique which has a sensitivity of $63.6 \%$ with respect to the egg recovery (Taira et al., 1983).

The number of eggs produced per day per worm (EPDPW) Eggs produced per day (EPD) were calculated by multiplying EPG by the weight of all the faeces collected in one day. The EPDPW was calculated by dividing EPD by the number of flukes detected at necropsy. The mean EPDPW values were calculated for the period 106 to 132 DAI for goat No. 802, and for the two periods 195 to 561 DAI and 707 to 732 DAI for goat No. 602; these periods were selected because the EPDPW values for these periods were relatively stable. Since the EPG count used in this study had a sensitivity of $63.6 \%$, the corrected EPDPW was calculated using EPG values obtained using the beads technique multiplied by 100/63.6 (Taira et al., 1983).

\section{Results}

\section{Clinical signs}

Apparent clinical signs associated with Fasciola infestation were not observed in the two goats during the experiment.

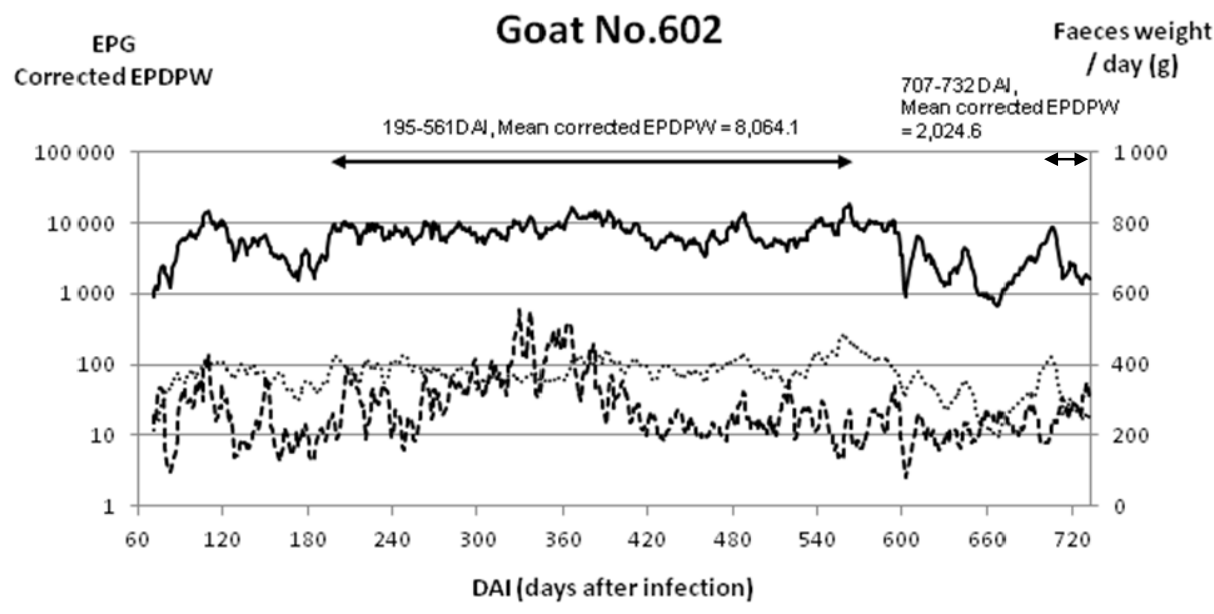

Fig. 2. Fluctuation in daily feces weight (broken line), eggs per gram (EPG) (dotted line) and corrected EPDPW (solid line) in a goat (goat No.602) experimentally infected with a single dose of 50 metacercariae of Fasciola gigantica (Japanese strain). Lines represent the moving average $(n=5)$. The goat was necropsied 732 days after infection (DAI), and five worms were detected.

Corrected EPDPW = feces weight in a day $(\mathrm{g}) \times \mathrm{EPG} /$ number of worms detected at necropsy x 100/63.6 (see text). Mean corrected EPDPW 
Table 1. Infection, necropsy and egg output from two goats experimentally infected with Fasciola gigantica (Japanese strain)

\begin{tabular}{|c|c|c|c|c|}
\hline Item & & Goat No. 802 & \multicolumn{2}{|c|}{ Goat No. 602} \\
\hline \multirow[t]{2}{*}{ Infection } & $\begin{array}{l}\text { Number of metacercariae } \\
\text { administered (single dose) }\end{array}$ & 50 & \multicolumn{2}{|c|}{50} \\
\hline & Body weight (date) & $18.5 \mathrm{~kg}$ (1 996.9.19) & \multicolumn{2}{|c|}{$12.2 \mathrm{~kg}(1995.2 .15)$} \\
\hline \multirow[t]{6}{*}{ Necropsy } & $\mathrm{DAI}^{1)}$ & 132 & \multicolumn{2}{|c|}{732} \\
\hline & Body weight & $10.5 \mathrm{~kg}$ & \multicolumn{2}{|c|}{$21.0 \mathrm{~kg}$} \\
\hline & Weight gain & $-8.0 \mathrm{~kg}$ & \multicolumn{2}{|c|}{$+8.8 \mathrm{~kg}$} \\
\hline & $\begin{array}{l}\text { Macroscopical lesion of livers } \\
\text { Number of flukes }{ }^{2)}(a) \\
\text { (recovery rate) }\end{array}$ & $\begin{array}{l}\text { Fig. } 3 \text { left } \\
23(46 \%)\end{array}$ & \multicolumn{2}{|c|}{ Fig. 3 right } \\
\hline & Total weight of flukes $\langle\mathrm{b}\rangle$ & $6.45 \mathrm{~g}$ & \multicolumn{2}{|c|}{$1.68 \mathrm{~g}$} \\
\hline & Mean weight of flukes $\langle\mathrm{b} / \mathrm{a}\rangle$ & $0.28 \mathrm{~g}$ & \multicolumn{2}{|c|}{$0.34 \mathrm{~g}$} \\
\hline \multirow[t]{5}{*}{ Egg output, etc. } & $\begin{array}{l}\text { Period to calculate EPDPW } \\
\text { Mean faeces weight produced/day } \\
(\mathrm{g})( \pm 95 \mathrm{CL})<\mathrm{c}>\end{array}$ & $\begin{array}{c}106-132 \text { DAI (Fig. 1) } \\
307.9( \pm 27.78)\end{array}$ & $\begin{array}{c}195-561 \text { DAI (Fig. 2) } \\
297.6( \pm 12.42)\end{array}$ & $\begin{array}{c}707 \text { - } 732 \text { DAI (Fig. 2) } \\
288.5( \pm 29.76)\end{array}$ \\
\hline & Mean EPG $( \pm 95 \mathrm{CL})<\mathrm{d}>$ & $462.4( \pm 36.96)$ & $90.8( \pm 4.31)$ & $24.1( \pm 5.39)$ \\
\hline & Mean EPD $( \pm 95 \mathrm{CL})<\mathrm{c} \times \mathrm{d}>$ & $138642.4( \pm 11189.21)$ & $25643.7( \pm 1,325.85)$ & $6438.2( \pm 1,058.07)$ \\
\hline & Mean EPDPW $( \pm 95 \mathrm{CL})<\mathrm{c} \times \mathrm{d} / \mathrm{a}>$ & $6027.9( \pm 486.49)$ & $5128.7( \pm 265.17)$ & $1287.7( \pm 211.61)$ \\
\hline & $\begin{array}{c}\text { Mean corrected EPDPW }( \pm 95 \mathrm{CL}) \\
<\text { EPDPWx100/63.6 }\end{array}$ & $9477.9( \pm 764.92)$ & $8064.1( \pm 416.94)$ & $2024.6( \pm 332.73)$ \\
\hline $\begin{array}{l}\text { 1) Days after inf } \\
\text { 2) Flukes detecte } \\
\text { 3) Eggs produce } \\
\text { 4) Detectability }\end{array}$ & $\begin{array}{l}\text { tion } \\
\text { in the livers of the goats are shown in Fi } \\
\text { per day per worm = feces weight in a day } \\
\text { Fasciola eggs using the beads technique }\end{array}$ & $\begin{array}{l}\text { EPG / number of flukes d } \\
6 \% \text { (Taira et. al., (1983) }\end{array}$ & d at necropsy & \\
\hline
\end{tabular}

\section{Faecal egg output}

Patency started in goat No. 802 at 64 DAI and in goat No. 602 at $<70$ DAI. The pattern of faecal egg output is presented in Figs. 1 and 2.

\section{Findings at necropsy}

The body weights of the goats at necropsy were $10.5 \mathrm{~kg}$ for goat No. 802 and $21.0 \mathrm{~kg}$ for goat No. 602. The weight gain of the goats after infection, calculated by subtracting

Goat No. 802

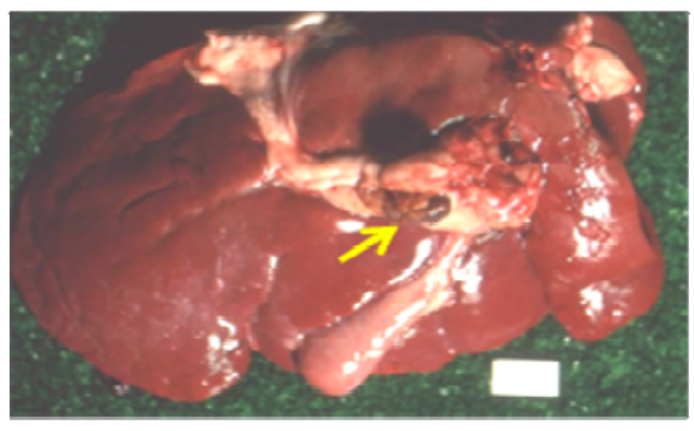

the weight of the goats at necropsy from their weight at inoculation, was $-8.0 \mathrm{~kg}$ for goat No. 802 and $+8.8 \mathrm{~kg}$ for goat No. 602 (Table 1). Goat No. 802 presented with an enlarged common bile duct, while goat No. 602 had a large cyst containing flukes on the diaphragmatic surface of the liver (Fig. 3). Twenty-three flukes (total wet weight of 6.45 g) were recovered from the liver of goat No. 802, and five flukes (total wet weight of $1.68 \mathrm{~g}$ ) were recovered from the liver of goat No. 602 (Fig. 4).
Goat No. 602

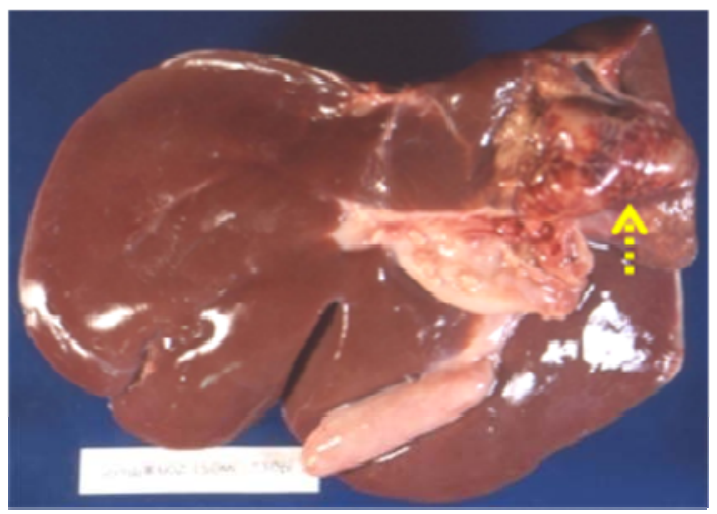

Fig. 3. Livers of goats experimentally infected with a single dose of 50 metacercariae of Fasciola gigantica (Japanese strain). (Left) Goat No.802 was necropsied at 132 days after infection (DAI). The bile duct was enlarged and a fluke was observed at the resected duct (solid arrow). (Right) Goat No.602 was necropsied at 732 DAI. The bile duct was enlarged and a large cyst containing worms was observed (dotted arrow). 


\section{Calculation of mean corrected EPDPW}

The mean weight of faeces produced per day ( $\pm 95 \%$ confidence limits) was $307.9 \mathrm{~g}( \pm 27.78 \mathrm{~g})$, mean EPG was $462.4( \pm 36.96)$, mean EPD was $138642.4( \pm 11$ 189.21) and mean EPDPW was $6027.9( \pm 486.49)$ at $106-132$ DAI for goat No. 802. These values for goat No. 602 at 195 - 561 DAI were $297.6( \pm 12.42), 90.8( \pm 4.31), 25643.7$ $( \pm 1325.85)$ and $5128.7( \pm 265.17)$, and at $707-732 \mathrm{DAI}$ were $288.5 \mathrm{~g}( \pm 29.76 \mathrm{~g}), 24.1$ ( \pm 5.39), $6 \quad 438.2$ $( \pm 1058.07)$ and $1287.7( \pm 211.61)$, respectively. The mean corrected EPDPW was $9477.9( \pm 764.92)$ for goat No. 802, and $8064.1( \pm 416.49)$ at $195-561$ DAI and 2 $024.6( \pm 332.73)$ at $707-732$ DAI for goat No. 602 (Table $1)$. The weight of faeces produced per day (g), EPG and corrected EPDPW for goat No. 802 are plotted with a moving average $(n=5)$ in Fig. 1 and those of goat No. 602 are plotted in Fig. 2, using a broken line, dotted line and solid line, respectively. EPG and corrected EPDPW were converted to natural logarithm values $(\log (\mathrm{x}+1))$ in Figs. 1 and 2 .
(1969) reported a gradual decrease in the egg production of flukes in response to an increase in the number of flukes in the liver of sheep, possibly due to the overcrowding effect. These authors also characterized liver infection by 1 to 100 flukes as being a light infection that causes chronic subclinical fasciolosis. The two goats herein used, each inoculated with 50 metacercariae, harboured 23 and 5 flukes in the liver and did not show any clinical signs. Since the light infection in this study may not have resulted in the overcrowding effect, the fecundity of flukes in the goats in the present study may not have been affected by the number of flukes in each host.

Rather, it appears that differences in either species or isolates of Fasciola are responsible for the differences in fecundity. Walker et al. (2006) reported differences in the EPDPW of different fluke isolates recovered from experimentally infected rats in vitro. These authors documented that the Fairhurst isolate, which was triclabendazole-susceptible, had EPDPW of 10 200, while the Oberon isolate, which is triclabendazole-resistant, was 3 623. The mean
Goat No. 802

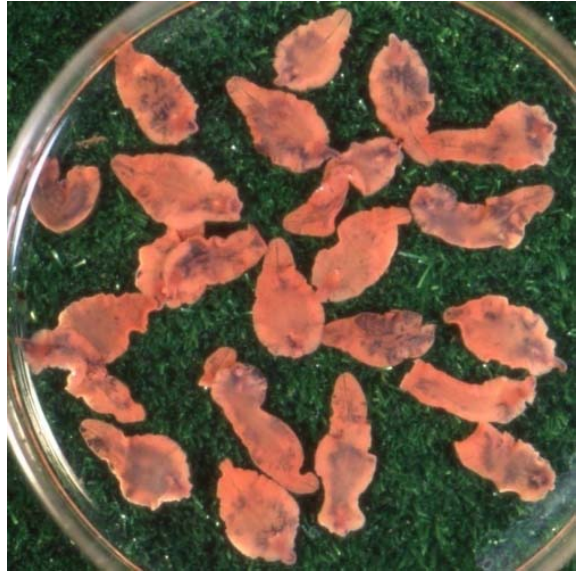

Goat No. 602

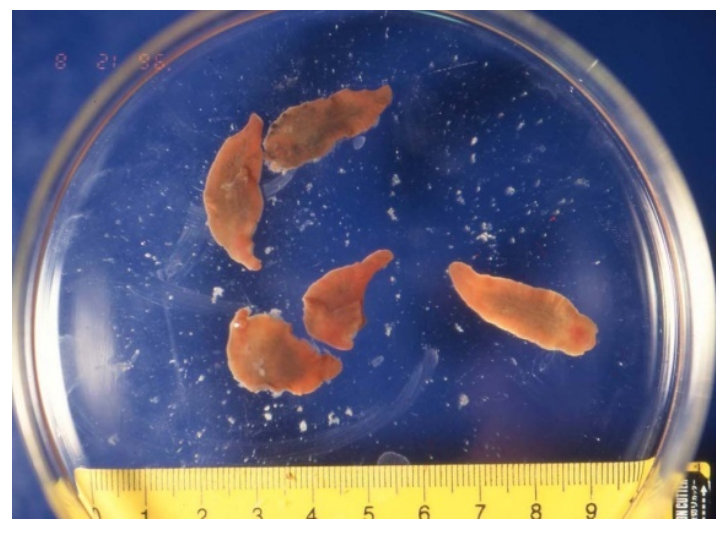

Fig. 4. Flukes detected at necropsy in goats experimentally infected with a single dose of 50 metacercariae of Fasciola gigantica (Japanese strain). (Left) Goat No.802 was necropsied at 132 days after infection (DAI ); 23 worms were found in the liver and the mean weight of the fluke was 0.28 g. (Right) Goat No.602 was necropsied at $732 \mathrm{DAI}$; five worms were found in the liver and the mean weight of fluke was $0.34 \mathrm{~g}$.

\section{Discussion}

The egg count data obtained in the present study was used to determine the fecundity of $F$. gigantica (Japanese strain). The mean corrected EPDPW calculated for goat No. 602 at 195 - 561 DAI was not markedly different from that obtained from goat No. 802 in the period $106-132$ DAI. However, the corrected EPDPW value for goat No. 602 at $707-732$ DAI constituted approximately $25 \%$ of that observed in the same goat at 195 - 561 DAI (Table 1). This reduction in EPDPW observed in goat No. 602 was likely due to senescence of the flukes in this animal. The comparatively large fluctuation was observed in the EPDPW in goat No. 602 at around 600 DAI, indicating that the activity of flukes appears to decline approximately 1.5 years after infection in goats.

The number of flukes in the liver also appears to affect the egg output capacity of Fasciola. Happich and Boray corrected EPDPW values in the goat No. 802 for the period 106 - 132 DAI and the goat No. 602 for the period $195-$ 561 DAI were most similar to those of the Fairhurst isolates. The $F$. gigantica (Japanese strain) is generally aspermic (Itagaki et al., 2005), but the aspermatogenesis does not appear to greatly affect the egg production in comparison with the Fairhurst isolate, a spermic $F$. hepatica. Happich and Boray (1969) reported that the mean EPDPW of $F$. hepatica in naturally infected sheep $(n=46)$ with less than 50 flukes in the liver was 25099 (range 6 288 - 50 924). The corrected EPDPW values in the goat No. 802 and that of the goat No. 602 for the period $195-$ 561 DAI were in the range given by Happich and Boray (1969).

Using data of Fasciola egg output obtained from goats that had been experimentally infected with a single inoculum of 50 metacercariae, the EPDPW of $F$. gigantica (Japanese strain) was estimated to range between approximately 8000 
- 10000 eggs. Although several factors may influence the fecundity of Fasciola in the field, the knowledge of the EPDPW estimated in the present study may assist faecal egg counts in the diagnosis of chronic fasciolosis caused by $F$. gigantica (Japanese strain).

\section{Acknowledgements}

We are grateful to Dr. V. Snabel from Parasitological Institute, Slovak Academy of Science, Slovak Republic, for giving us valuable advice. We also thank to Dr. F. H. M. Borgsteede from the Central Veterinary Institute of Wageningen University, The Netherlands, for a critical reading to the manuscript.

\section{References}

Alicata, J. E., Swanson, L. E. (1941): Observations on the longevity of the liver fluke, Fasciola gigantica, in cattle. Am. J. Vet. Res., 2: $417-418$

BONITA, R., TAIRA, N. (1996): Faecal examination of Fasciola eggs fixed with formalin solution using the beads technique. Vet. Parasitol., 67: 269 - 273. DOI: 10.1016/S0 304-4017(96)00990-9

BORAY, J. C. (1967): Studies on experimental infections with Fasciola hepatica, with particular reference to acute fascioliasis in sheep. Ann. Trop. Med. Parasitol., 61: $439-$ 450

HAPPICH, F. A., BorAY, J. C. (1969): Quantitative diagnosis of chronic fasciolosis. 2. The estimation of daily total egg production of Fasciola hepatica and the number of adult flukes in sheep by faecal egg counts. Aust. Vet. J., 45: $329-331$
ItAGaKi, T., Tsutsumi, K. (1998). Triploid form of Fasciola in Japan: genetic relationships between Fasciola hepatica and Fasciola gigantica determined by ITS-2 sequence of nuclear rDNA. Int. J. Parasitol., 28 (5): 777 781. DOI:10.1016/S0020-7519(98)00037-X

Itagaki, T., KiKawa, M., Sakaguchi, K., Shimo, J., Terasaki, K., Shibahara, T., FuKuda, K. (2005). Genetic characterization of parthenogenic Fasciola sp. in Japan on the basis of the sequences of ribosomal and mitochondrial DNA. Parasitology, 131 (5): 679 - 685. DOI: 10.1017/S0031182005008292

TAIRA, N., SuzUKI, K., BORAY, J. C. (1983): Detection and quantitation of Fasciola eggs in cattle feces using the beads technique. Jpn. J. Parasitol., 32 (4): 279 - 286

TAIRA, N., YoshifuJI, H., BORAY, J. C. (1997): Zoonotic potential of infection with Fasciola sp. by consumption of freshly prepared raw liver containing immature flukes. Int. J. Parasitol., 27 (7): 775 - 779. DOI: 10.1016/S0020-7519 (97)00038-6

TAIRA, K., YoshifuJI, H., TAIRA, N. (2000): Long term daily EPG counts in cattle and goats after a single infection with Fasciola gigantica (Japanese strain). Helminthologia, 37 (3): $143-145$

Walker, S. M., Hoey, E., Fletcher, H., Brennan, G., FAIRWEATHER, I., TRUdGetT, A. (2006): Stage-specific differences in fecundity over the life-cycle of two characterized isolates of the liver fluke, Fasciola hepatica. Parasitology, 133: 209 - 216. DOI: 10.1017/S003118200600014X Yoshihara, S., Hung, N. H., Hung, N. P., Goto, N. (1998): An erratic parasitism found in the lungs of sheep during experimental infection with Fasciola gigantica (Japanese strain). J. Helminthol., 72 (3): 227 - 230 